\title{
Enhancing Nanocrystallite Si Electroluminescence by Suppressing Oxygen Decomposition in High-Temperature and Low-Plasma-Power PECVD
}

\author{
Chun-Jung Lin $^{\mathrm{a}}$ and Gong-Ru Lin ${ }^{\mathrm{b}, \mathrm{z}}$ \\ ${ }^{a}$ Department of Photonics and Institute of Electro-Optical Engineering, National Chiao Tung University, \\ Hsinchu 300, Taiwan \\ ${ }^{b}$ Graduate Institute of Electro-Optical Engineering and Department of Electrical Engineering, National \\ Taiwan University, Taipei 106, Taiwan
}

\begin{abstract}
This work demonstrates enhanced electroluminescence and quantum efficiency of a metal-SiO $-\mathrm{Si}$ light-emitting diode (MOSLED) fabricated on nanocrystallite $\mathrm{Si}$ (nc-Si)-embedded $\mathrm{SiO}_{x}$ plasma-enhanced chemical vapor deposition (PECVD) grown at high substrate temperature and threshold plasma power. Electron energy loss spectroscopy indicates that the energy loss of the primary electron transmitted throughout $\mathrm{Si}$-rich $\mathrm{SiO}_{x}$ is reduced from 110 to $106 \mathrm{eV}$ due to the formation of nc-Si. At low plasma power condition, the required dissociation energy of a $\mathrm{N}_{2} \mathrm{O}$ molecule exceeds that of a $\mathrm{SiH}_{4}$ molecule, while increasing the deposition temperature during PECVD growth facilitates the out-diffusion of adsorbed oxygen atoms. Such enhanced deposition of $\mathrm{Si}$-rich $\mathrm{SiO}_{x}$ with excess $\mathrm{Si}$ atoms and dense nc-Si after annealing is observed. As the deposition temperature for the Si-rich $\mathrm{SiO}_{x}$ increases from 300 to $400^{\circ} \mathrm{C}$, the electroluminescent power and quantum efficiency of the nc-Si-based MOSLED are both improved by more than 1 order of magnitude. The output power, turn-on voltage, and internal and external quantum efficiency of the indium tin oxide/ $\mathrm{SiO}_{x}: \mathrm{nc}-\mathrm{Si} / \mathrm{p}-\mathrm{Si} / \mathrm{Al}$ diode that was prepared at a substrate temperature of $400^{\circ} \mathrm{C}$ are $47 \mathrm{nW}$ at $54 \mu \mathrm{A}, 54.5 \mathrm{~V}$, $5 \times 10^{-4}$, and $1.6 \times 10^{-5}$, respectively.

(C) 2007 The Electrochemical Society. [DOI: 10.1149/1.2747535] All rights reserved.
\end{abstract}

Manuscript submitted October 17, 2006; revised manuscript received April 17, 2007. Available electronically June $25,2007$.

Nanocrystallite Si structures that exhibit the quantum confinement effect have led to the development of novel Si-based functional devices such as light-emitting diodes, resonant tunneling diodes, and single-electron transistors, etc. ${ }^{1-3}$ In particular, most investigations on preparing silicon oxide or nitride with buried $\mathrm{Si}$ nanocrystals (nc-Si) in matrices have been performed using plasmaenhanced chemical vapor deposition (PECVD), in which pure monosilane $\left(\mathrm{SiH}_{4}\right)$ and nitrous oxide $\left(\mathrm{N}_{2} \mathrm{O}\right)$ or ammonia $\left(\mathrm{NH}_{3}\right)$ are decomposed at high plasma power from 100 to $450 \mathrm{~W}$. ${ }^{4,5}$ Few studies have addressed the deposition of Si-rich $\mathrm{SiO}_{2}\left(\mathrm{SiO}_{x}\right)$ using lowplasma-power PECVD methods. Recently, the authors demonstrated some specific features of the $\mathrm{SiO}_{x}$ thin film grown at high plasma power and low substrate temperatures for optimizing the growth of $\mathrm{SiO}_{x}$ and the precipitation of nc-Si by conventional PECVD. ${ }^{6}$ The number of excess $\mathrm{Si}$ atoms in such a nonstoichiometric $\mathrm{SiO}_{x}$ matrix is increasing markedly with temperature at substrate temperatures as low as $30-100^{\circ} \mathrm{C}$ because of the enhanced phase separation between $\mathrm{Si}$ and $\mathrm{SiO}_{2}$ during low-substrate-temperature deposition. In other words, a normal PECVD growth condition at high radio frequency (rf) power and high substrate temperature for the stoichiometric $\mathrm{SiO}_{2}$ deposition is detrimental to the synthesis of nc-Si. However, high rf power inevitably contributes to plasma treatment on the substrate surface, which may severely worsen the electrical performance of nearby complementary metal oxide semiconductor (CMOS) devices and circuitry. A low-plasma-power PECVD synthesis of $\mathrm{SiO}_{x}$ film is therefore necessary to prevent possible damage, which was seldom discussed in previous investigations.

This work investigates the synthesis of the $\mathrm{SiO}_{x}$ film by suppressing oxygen decomposition in a low-plasma-power PECVD at high substrate temperatures. The effects of chamber pressure, $\mathrm{SiH}_{4} / \mathrm{N}_{2} \mathrm{O}$ fluence ratio, and plasma power on the excess Si ratio are characterized using continuous-wave and time-resolved photoluminescence (PL). The morphology and density of synthesized nc-Si is monitored by high-resolution transmission electron microscopy (HRTEM). In particular, the separation of $\mathrm{Si}$ and $\mathrm{SiO}_{2}$ phases, the formation of nc-Si, and their transition to the crystalline phase were investigated using electron energy loss spectroscopy (EELS). The evolution of the electroluminescence (EL) of a metal-oxidesemiconductor light-emitting diode (MOSLED) that was fabricated

ż-mail: grlin@ntu.edu.tw on the PECVD-grown and nc-Si-embedded $\mathrm{SiO}_{x}$ at a high deposition temperature and threshold plasma power is also obtained.

\section{Experimental}

The plasma power was set as low as $40 \mathrm{~W}$, and the $\mathrm{SiO}_{x}$ films were grown on p-type $\mathrm{Si}(100)$ substrate using a PECVD system with different $\mathrm{SiH}_{4} / \mathrm{N}_{2} \mathrm{O}$ fluence ratios, chamber pressures, and substrate temperatures. The $\mathrm{SiH}_{4}$ fluence remained at $20 \mathrm{sccm}$, whereas the $\mathrm{N}_{2} \mathrm{O}$ fluence varied from 105 to $130 \mathrm{sccm}$. After deposition, the samples were annealed in a quartz furnace with flowing $\mathrm{N}_{2}$ at $1100^{\circ} \mathrm{C}$ for $15-180 \mathrm{~min}$. The room-temperature $\mathrm{PL}$ of the $\mathrm{SiO}_{x}$ films, pumped by an Nd yttrium aluminum garnet (YAG) laser at a wavelength and an average intensity of $532 \mathrm{~nm}$ and $61 \mathrm{~W} / \mathrm{cm}^{2}$, respectively, was analyzed using a fluorescence spectrophotometer (CVI, DK240 with resolution of $0.06 \mathrm{~nm}$ ) and a photomultiplier (Hamamatsu, model R928). To characterize the orientation and size of nc-Si, the bright-field cross-sectional image was taken using HRTEM (JEOL 4000EX) with a primary electron energy of $400 \mathrm{keV}$ and a point-to-point resolution of $0.18 \mathrm{~nm}$. In the time resolved PL (TRPL) experiment, the $\mathrm{SiO}_{x}$ samples were pumped by a third-harmonic-generated YAG laser (NY 60, Continuum) at $355 \mathrm{~nm}$. The repetition rate, the pulse at the full width at half maximum (fwhm), and the average power of the YAG laser are $1 \mathrm{~Hz}$, $60 \mathrm{ps}$, and $0.5 \mathrm{~mJ} / \mathrm{pulse}$, respectively. The TRPL signal was detected by a time-correlated single-photon counting system and the nc-Sidependent luminescent lifetime was determined using Einstein's two-level quantized radiation model. ${ }^{7}$ The PL intensity of nc-Si can be approximated by $I=\eta \sigma \phi(t) N / \tau$, where $\sigma$ is the absorption cross section of nc-Si that can be determined theoretically using $\sigma$ $=\lambda^{2} / 8 \pi \Delta v \tau$ (where $\lambda$ and $\Delta v$ are the peak wavelength and the linewidth of the PL spectrum), ${ }^{8,9} \eta$ is a relative coefficient, $\tau$ is the lifetime of nc-Si, $\phi(t)$ is the pumping flux, and $N$ is the nc-Si concentration. $^{10,11}$

\section{Results and Discussion}

Effect of $\mathrm{N}_{2} \mathrm{O} / \mathrm{SiH}_{4}$ ratio on density of nc-Si in PECVD-grown $\mathrm{SiO}_{x}$ film.- Varying the $\mathrm{N}_{2} \mathrm{O} / \mathrm{SiH}_{4}$ fluence ratio controls the $\mathrm{Si}$ composition in the deposited $\mathrm{SiO}_{x}$, which strongly influences the size and density of the nc-Si after annealing. In particular, the optimal annealing condition could also be changed for the $\mathrm{SiO}_{x}$ grown at different $\mathrm{N}_{2} \mathrm{O} / \mathrm{SiH}_{4}$ fluence ratios. Controlling $\mathrm{SiH}_{4}$ fluence does not yield a predictable result as the decomposition rate of $\mathrm{Si}$ is well 


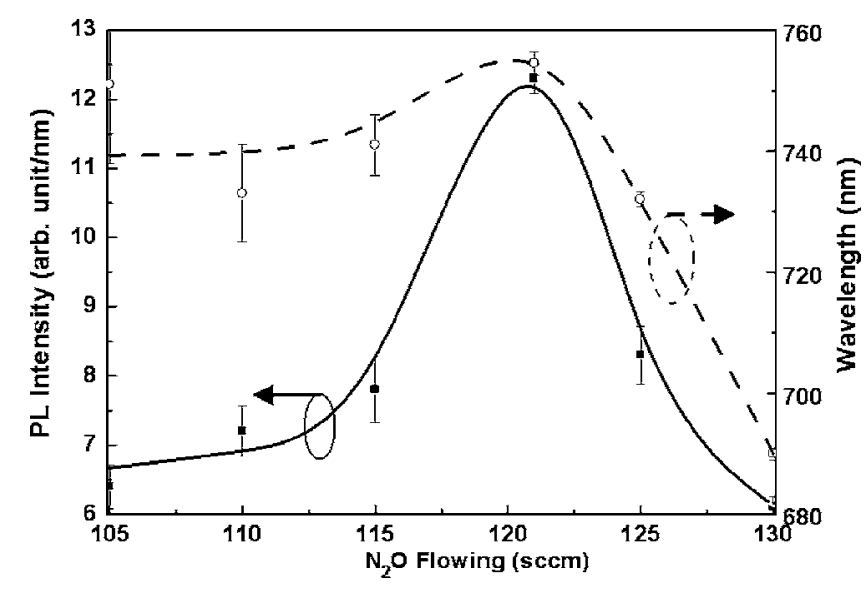

Figure 1. PL intensity and peak wavelength as a function of $\mathrm{N}_{2} \mathrm{O}$ fluence.

beyond that of the oxygen under such conditions. In this case, $\mathrm{N}_{2} \mathrm{O}$ fluence dominates the low-plasma-power PECVD growth. The optimal annealing times for $\mathrm{SiO}_{x}$ samples prepared under different $\mathrm{N}_{2} \mathrm{O}$ fluences are tentatively varied, which is attributed to the evolutional thermal conductivity of the $\mathrm{SiO}_{x}$ caused by the variation in the density of excess $\mathrm{Si}$ atoms in the $\mathrm{SiO}_{x}$ film prepared under different $\mathrm{N}_{2} \mathrm{O}$ fluences. After furnace annealing at $1100^{\circ} \mathrm{C}$ for $60 \mathrm{~min}$, the highest PL intensity and the largest peak wavelength among these samples were observed from the sample that was prepared at an $\mathrm{N}_{2} \mathrm{O}$ fluence of $120 \mathrm{sccm}$, as shown in Fig. 1. The highest excess $\mathrm{Si}$ condition was observed in the $\mathrm{SiO}_{x}$ sample that was prepared at an $\mathrm{N}_{2} \mathrm{O}$ fluence of $120 \mathrm{sccm}$. As the $\mathrm{N}_{2} \mathrm{O}$ fluence increased from 105 to $120 \mathrm{sccm}$, the PL intensity doubled. However, the PL intensity decreased by a factor of three as the $\mathrm{N}_{2} \mathrm{O}$ fluence was increased further to $130 \mathrm{sccm}$. The peak PL wavelength concurrently increased from 733 to $754.5 \mathrm{~nm}$ as the $\mathrm{N}_{2} \mathrm{O}$ fluence increased from 105 to $120 \mathrm{sccm}$ and then decreased to $690 \mathrm{~nm}$ as the $\mathrm{N}_{2} \mathrm{O}$ fluence increased to $130 \mathrm{sccm}$ or higher. Increasing the $\mathrm{N}_{2} \mathrm{O}$ fluence leads to the adsorption of more oxygen atoms on the substrate, improving oxidation and contributing to the smaller size of nc-Si, which in turn blue-shifts the PL peak after annealing. Both the size and density of nc-Si then decrease. In contrast, insufficient oxygen atoms were decomposed at $\mathrm{N}_{2} \mathrm{O}$ fluences of under $120 \mathrm{sccm}$, yielding dense $\mathrm{Si}$ atoms and contributing to the larger size of nc-Si with smaller density after annealing. In addition to the observation of decreasing PL intensity, the less-decreasing trend of PL wavelength correlates closely with the almost constant size of nc-Si.

As the annealing time increases from 15 to $60 \mathrm{~min}$, the lifetimes of the nc-Si in $\mathrm{SiO}_{x}$ films decrease from 52 to $20 \mu \mathrm{s}$, as shown in Fig. 2 and Table I. A stretched exponential function, $I(t)$ $=I_{0} \exp (-t / \tau)$, was used to fit the data, in which $\tau$ is an effective decay time. The luminescent lifetime increases from 20 to $52 \mu \mathrm{s}$ as the nc-Si size extends from 4.0 to $4.2 \mathrm{~nm}$. Moreover, the nc-Si lifetime increases smoothly with the increment of the nc-Si size, as determined by Garcia et al. ${ }^{12}$ The theoretical carrier-transition equation can be simplified to $I_{\mathrm{PL}} \propto \sigma \phi(t) 1 / \tau_{\mathrm{PL}} N_{\text {nc-Si }},{ }^{12,13}$ and the variation of the nc-Si density can be estimated by the PL intensity $\left(I_{\mathrm{PL}}\right)$ and the lifetime $\left(\tau_{\mathrm{PL}}\right)$ of nc-Si, where $\sigma$ and $\phi(t)$ are the emission (absorption) cross section of nc-Si and the pumping photon flux density obtained from the pumping power, respectively. The product of these two terms for different annealing-time samples is a constant. As the annealing time increases from 15 to $60 \mathrm{~min}$, the density of nc-Si decreases from 8.3 to $1.2 \times 10^{18} \mathrm{~cm}^{-3}$, which correlates closely with the evolution of measured PL, as reported by Augustine et al. ${ }^{13}$ In principle, a longer annealing time essentially produces larger size and less-dense nc-Si because of the accumulation of small-size nc-Si and the unchanged density of $\mathrm{Si}$ atoms in the PECVD-grown $\mathrm{SiO}_{x}$ sample. The planar-view HRTEM image of the



Figure 2. TRPL spectra of nc-Si embedded in PECVD-grown $\mathrm{SiO}_{x}$ samples for different annealing times.

PECVD-grown $\mathrm{SiO}_{x}$ sample that is annealed for 15 min reveals that the average diameter of nc-Si is about $4.2 \mathrm{~nm}$, as shown in Fig. 3. The fwhm of the size distribution of the nc-Si embedded in the $\mathrm{SiO}_{x}$ film is estimated to be $\pm 1.4 \mathrm{~nm}$, as shown in Fig. 4. The estimated volume density of the nc-Si buried in the 15 min annealed PECVDgrown $\mathrm{SiO}_{x}$ film is about $8.3 \times 10^{18} \mathrm{~cm}^{-3}$. In our experiment, the $\mathrm{PL}$ intensity of PECVD-grown $\mathrm{SiO}_{x}$ samples is the largest in the sample that is annealed for 15 min (see Fig. 5). When the annealing time gradually increases to $60 \mathrm{~min}$, the excessive thermal energy

Table I. Wavelength, size, lifetime, and estimated density of nc-Si in $\mathrm{SiO}_{x}$ films after annealing for 15,30 , and $60 \mathrm{~min}$.

\begin{tabular}{lccc} 
& $15 \mathrm{~min}$ & $30 \mathrm{~min}$ & $60 \mathrm{~min}$ \\
\hline Wavelength $(\mathrm{nm})$ & 761 & 751 & 743 \\
nc-Si size $(\mathrm{nm})$ & 4.2 & 4.1 & 4.0 \\
Lifetime $(\mu \mathrm{s})$ & 52 & 31 & 20 \\
Estimated density $\left(\mathrm{cm}^{-3}\right)$ & $8.3 \times 10^{18}$ & $2.4 \times 10^{18}$ & $1.2 \times 10^{18}$
\end{tabular}

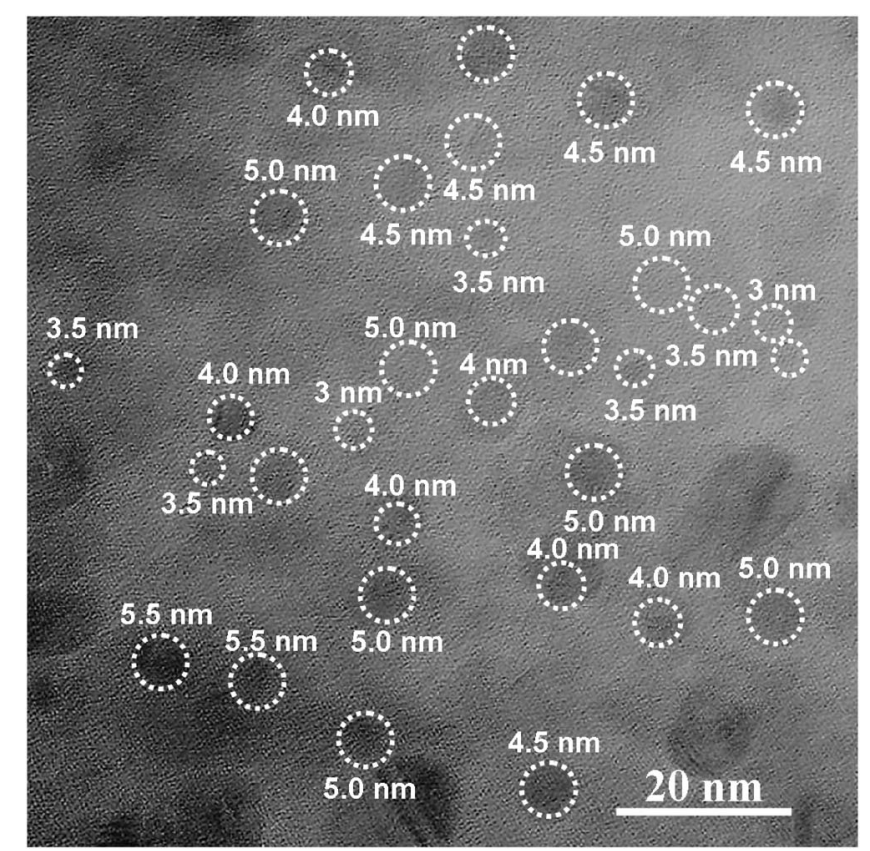

Figure 3. Planar-view HRTEM picture of 15 min annealed PECVD-grown $\mathrm{SiO}_{x}$ film. 


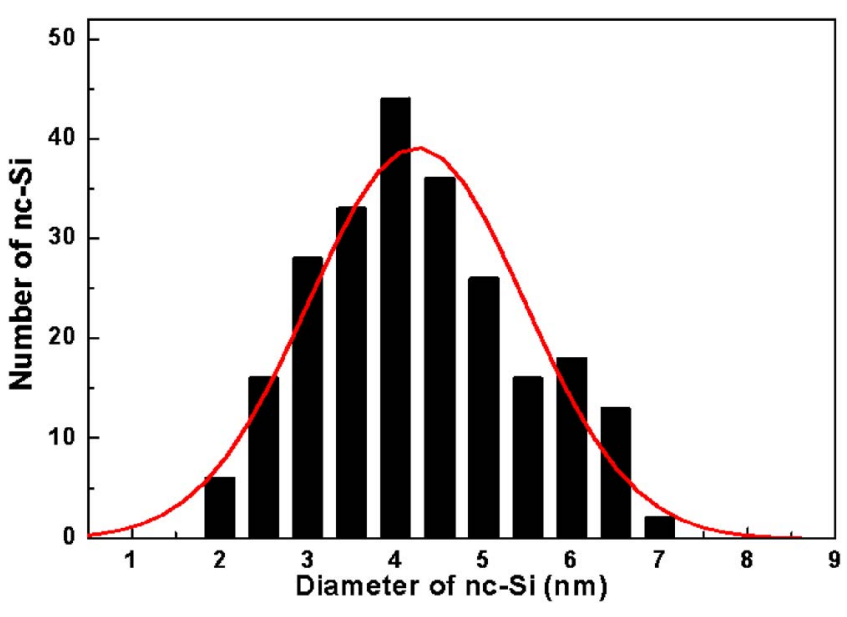

Figure 4. (Color online) Size distribution of nc-Si in the 15 min annealed PECVD-grown $\mathrm{SiO}_{x}$ film.

causes the regrowth of the $\mathrm{SiO}_{2}$ matrix as well as the reoxidation of nc-Si. This fact can be proved by the slight blue-shift of the PL as the annealing time increases and the intensity decreases. It also is highly consistent with the result of the carrier rate equations. Indeed, the PL peak wavelengths exhibit a blue-shift from 760 to $742 \mathrm{~nm}$, which correlates well with the decrease in the size of the nc-Si. Theoretically, the dominant size of $\mathrm{nc}-\mathrm{Si}$ decreases from 4.5 to $4.2 \mathrm{~nm}$ and the width of the size distribution of nc-Si increases as annealing duration lengthens from 15 to $60 \mathrm{~min}$, according to Delerue's equation ${ }^{12,14}$ of $E(\lambda)=1.12+\left(3.73 / d^{1.39}\right)$, where $E(\lambda)$ is the wavelength-related energy and $d$ is the size of nc-Si. Furthermore, the spectral linewidth of PL spectra $(\Delta \lambda)$ increases from 137 to $187 \mathrm{~nm}$, which also corroborates the increase in the width of the size distribution $(\Delta d)$ from \pm 1.4 to $\pm 1.7 \mathrm{~nm}$, as shown in Fig. 6.

The maximum PL intensities of 60 min annealed samples prepared under different chamber pressures between 40 and 70 mTorr increase with annealing time, as shown in Fig. 7. At a $\mathrm{SiH}_{4} / \mathrm{N}_{2} \mathrm{O}$ fluence ratio of 1:6, the optimal chamber pressure for the PECVDgrown $\mathrm{SiO}_{x}$ sample with the highest PL intensity is 60 mTorr, as presented in the inset of Fig. 7. The PL intensity decreases as the process pressure decreases to less than $60 \mathrm{mTorr}$. The presence of insufficient reactants at a process pressure of under 60 mTorr contributed to the lower excess $\mathrm{Si}$ ion density and the difficulty of precipitating nc-Si.

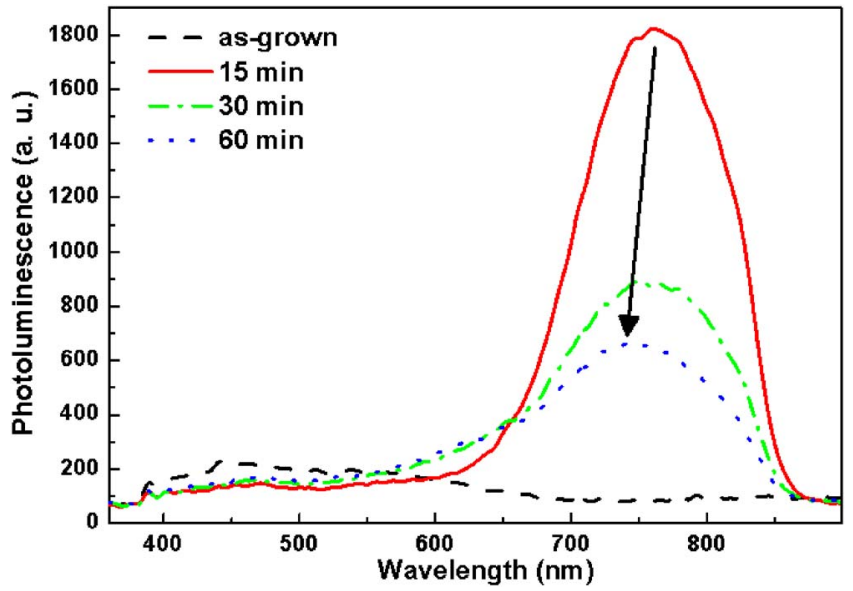

Figure 5. (Color online) PL spectra of PECVD-grown $\mathrm{SiO}_{x}$ samples annealed from 15 to $60 \mathrm{~min}$.

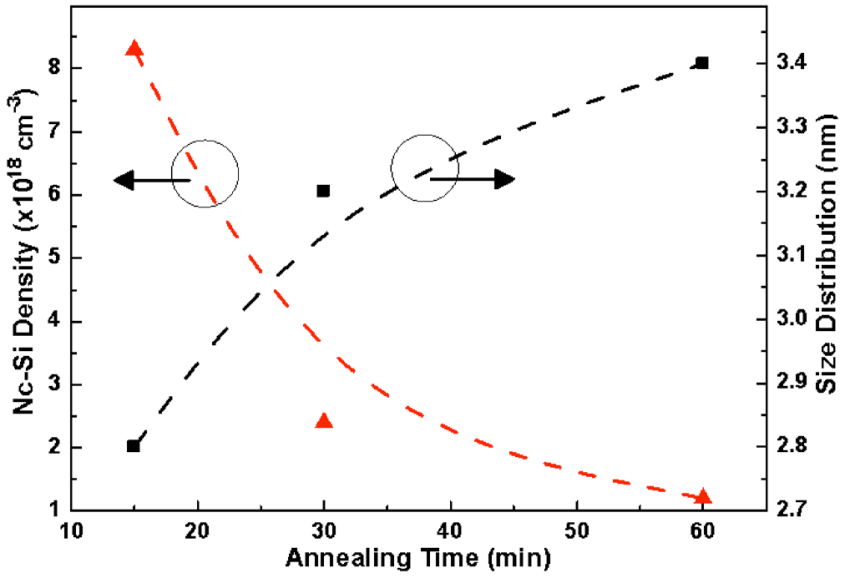

Figure 6. (Color online) Density and size distribution of nc-Si buried in annealed $\mathrm{SiO}_{x}$ film as a function of annealing time.

Effect of substrate temperature on density of $n c$-Si.- In EELS analysis, the primary electron that is incident the standard Si matrix with covalent $\mathrm{Si} \equiv \mathrm{Si}$ bonds loses energy because of the versatile up-transitions of the inner shell electrons at the $2 \mathrm{~s}$ and $2 \mathrm{p}$ orbits of the $\mathrm{Si}$ atom. Typically, $\mathrm{L}_{2,3}$ denotes the transition of electrons at $2 \mathrm{p}_{1 / 2}$ and $2 \mathrm{p}_{3 / 2}$ orbits, and $\mathrm{L}_{1}$ denotes that for electrons at $2 \mathrm{~s}_{1 / 2}$ in $\mathrm{Si}$. These interactions contribute to the relative peak observed at different energy losses of the EELS spectrum, in which the first peak corresponds to the up-transition of electrons from the $2 p_{1 / 2}$ or $2 p_{3 / 2}$ level to the vacuum. The loss of kinetic energy of the primary electron that is caused by a $\mathrm{Si}-\mathrm{L}_{2,3}$ transition in a standard $\mathrm{Si}$ substrate is about $101 \mathrm{eV}$, as shown in Fig. 8. Alternatively, the $\mathrm{Si}-\mathrm{L}_{2,3}$ transition in a standard $\mathrm{SiO}_{2}$ consumes more of the energy of the primary electron, shifting the corresponding EELS peak to $110 \mathrm{eV}$ with a fwhm of $4.1 \mathrm{eV}$. In the PECVD-grown $\mathrm{SiO}_{x}$ sample, the spectral linewidth is broadened to $7.7 \mathrm{eV}$ as the stoichiometric condition of the $\mathrm{SiO}_{x}$ deviates from that of the $\mathrm{SiO}_{2}$. The EELS intensity of the $\mathrm{Si}-\mathrm{L}_{2,3}$ transition in the PECVD-grown $\mathrm{SiO}_{x}$ sample is much lower than that of standard $\mathrm{SiO}_{2}$ because the PECVD-grown $\mathrm{SiO}_{x}$ film is amorphous. After $30 \mathrm{~min}$ of furnace-annealing, the loss of the kinetic energy of the primary electron that is due to the $\mathrm{Si}-\mathrm{L}_{2,3}$ transition in the annealed $\mathrm{SiO}_{x}$ sample decreases to $106 \mathrm{eV}$. Moreover, the EELS intensity at a kinetic energy loss of $101 \mathrm{eV}$ in the $30 \mathrm{~min}$ annealed sample is 2 orders of magnitude larger than that in the PECVD-grown $\mathrm{SiO}_{x}$ film, which is attributed to the formation of nc-Si. The excess Si atoms precipitate into nc-Si in the PECVD-

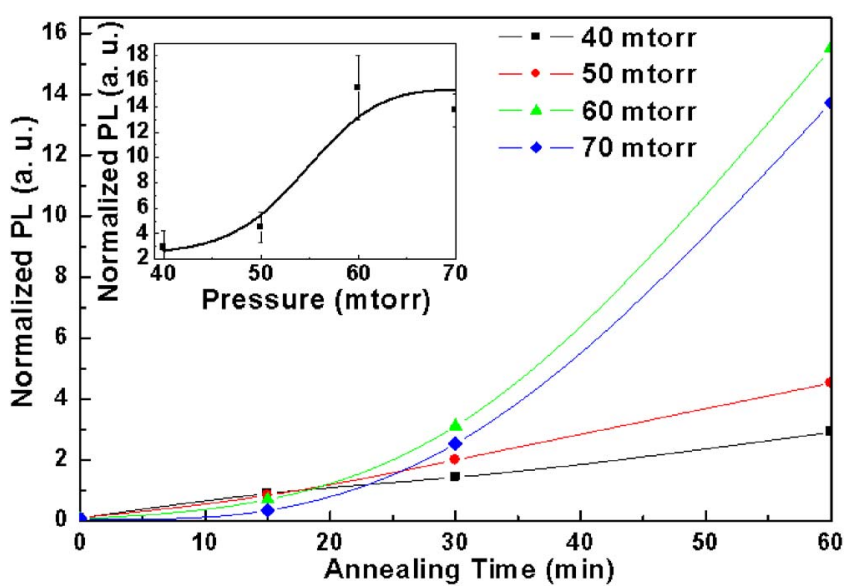

Figure 7. (Color online) PL as function of annealing time at different process pressures. 


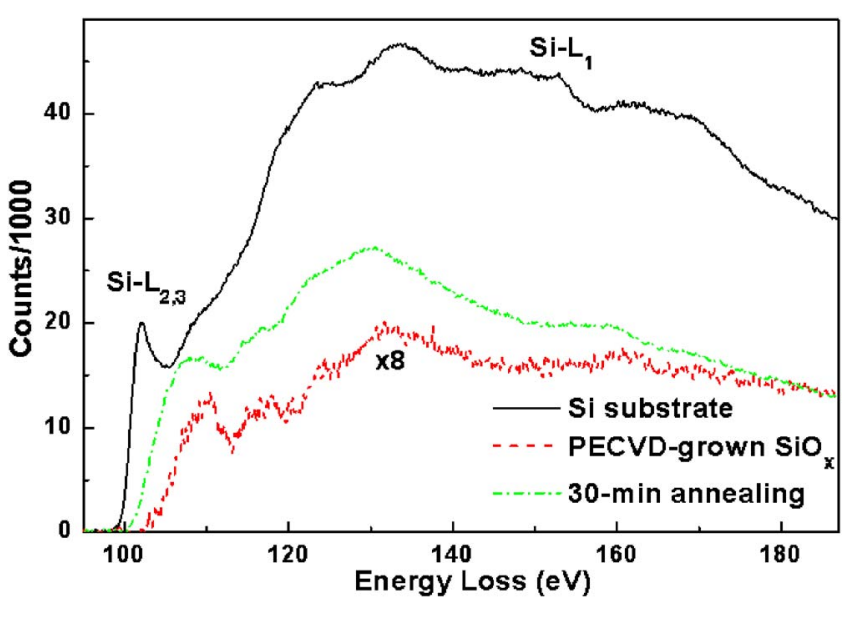

Figure 8. (Color online) EELS spectra of pure $\mathrm{Si}$, as-grown $\mathrm{SiO}_{x}$ and $30 \mathrm{~min}$ annealed samples.

grown $\mathrm{SiO}_{x}$ sample and the lower kinetic energy loss of a $\mathrm{Si}-\mathrm{L}_{2,3}$ transition in crystallite $\mathrm{Si}$ cause the combined kinetic energy loss of a $\mathrm{Si}-\mathrm{L}_{2,3}$ transition in an annealed $\mathrm{SiO}_{x}$ sample with nc-Si to be significantly lower than that in a PECVD-grown $\mathrm{SiO}_{x}$ sample without nc-Si. Therefore, the formation of nc-Si can be verified by comparing the EELS spectra of the Si substrate, the as-PECVD-grown $\mathrm{SiO}_{x}$ film, and the furnace-annealed $\mathrm{SiO}_{x}$ film, because the kinetic energy loss of a $\mathrm{Si}-\mathrm{L}_{2,3}$ transition varies with the chemical structure.

After furnace annealing at $1100^{\circ} \mathrm{C}$ for $60 \mathrm{~min}$, the PL spectra of samples that are deposited at various substrate temperatures exhibit an nc-Si-dependent broad spectrum between 670 and $850 \mathrm{~nm}$ with a slightly broad fwhm linewidth from 101 to $106 \mathrm{~nm}$ as the substrate temperature increases from 200 to $400^{\circ} \mathrm{C}$, as shown in Fig. 9 . The PL peak wavelengths of the samples that are deposited at substrate temperatures of $200,300,350$, and $400^{\circ} \mathrm{C}$ shift from 732 to $754 \mathrm{~nm}$, as shown in the inset of Fig. 9, which corresponds to the increase in the size of nc-Si and the increase in the density of the excess Si atom. The normalized PL intensity of the sample deposited at a substrate temperature of $400^{\circ} \mathrm{C}$ is six times higher than that of the sample deposited at $200^{\circ} \mathrm{C}$. At low process power (near the threshold plasma power), reactants such as $\mathrm{SiH}_{4}$ and $\mathrm{N}_{2} \mathrm{O}$ are hardly dissociated. Because the dissociation energies of the $\mathrm{SiH}_{4}$ and $\mathrm{N}_{2} \mathrm{O}$ molecules are 75.6 and $101.5 \mathrm{kcal} / \mathrm{mol},{ }^{15,16}$ respectively, the $\mathrm{N}_{2} \mathrm{O}$ molecule is less easily dissociated than the $\mathrm{SiH}_{4}$ molecule, resulting in the deposition of excess $\mathrm{Si}$ atoms and contributing to the higher

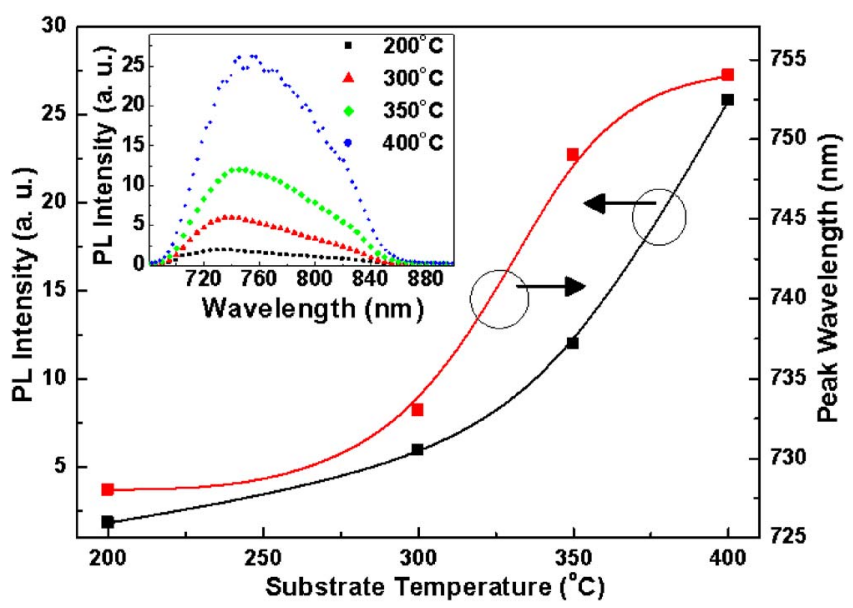

Figure 9. (Color online) PL intensity and peak wavelength as a function of substrate temperature.

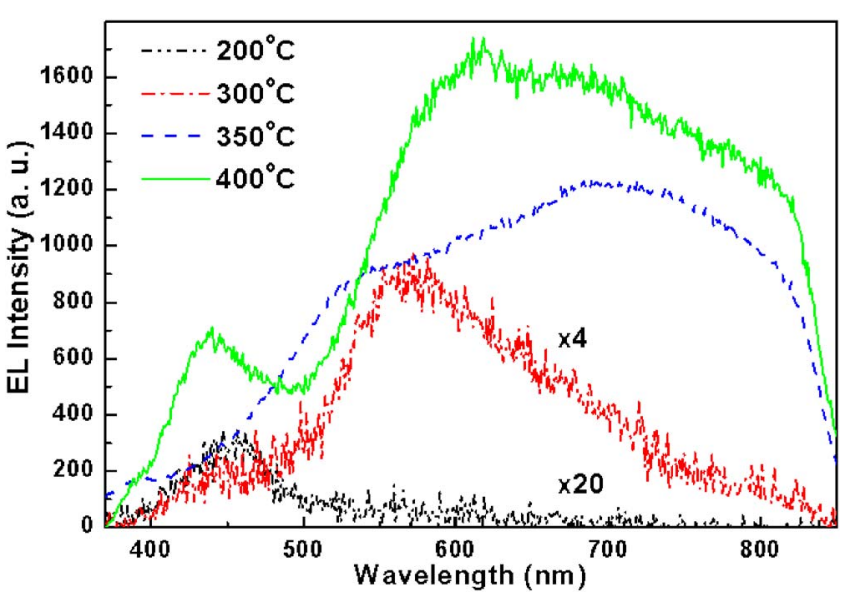

Figure 10. (Color online) EL spectra of samples prepared under different substrate temperatures.

density of nc-Si. Furthermore, the weight of a Si atom exceeds that of oxygen and hydrogen atoms, facilitating the deposition of Si atoms. Wong et al. ${ }^{17}$ have also demonstrated the deposition of the carbon-doped hydrogenated silicon oxide film using PECVD at substrate temperatures from 200 to $400^{\circ} \mathrm{C}$ and found that the quantity of the Si-O stretching bond decreases as the deposition temperature increases, based on Fourier transform infrared spectroscopy measurements. This result is attributed to the deposition of a few oxygen atoms and the introduction of $-\mathrm{CH}$ and $-\mathrm{CH}_{3}$ groups during the process at a high substrate temperature.

The increase of the peak intensities in the EL spectra of conventional indium tin oxide (ITO)/SiO ${ }_{x}: \mathrm{nc}-\mathrm{Si} / \mathrm{p}-\mathrm{Si} / \mathrm{Al}$ MOSLEDs at various substrate temperatures from 200 to $400^{\circ} \mathrm{C}$ is well correlated with the evolution of the intensity in the PL spectra, as shown in Fig. 10. The EL intensity of the sample at a substrate temperature of $200^{\circ} \mathrm{C}$ is very low because the density of nc-Si is low. At lower substrate temperatures, oxygen atoms are easily adsorbed onto the substrate and hardly diffuse into free space. Therefore, the density of oxygen atoms in the PECVD-grown $\mathrm{SiO}_{x}$ film that is prepared at low substrate temperatures exceeds that of such a film prepared at a high substrate temperatures. The aforementioned reaction on the substrate contributes to the formation of a stoichiometric $\mathrm{SiO}_{2}$ matrix. After furnace annealing at $1100^{\circ} \mathrm{C}$ for $60 \mathrm{~min}$, sufficient oxygen atoms react with excess $\mathrm{Si}$ atoms to form the $\mathrm{SiO}_{2}$ matrix. Therefore, the sample that is prepared at a substrate temperature of $200^{\circ} \mathrm{C}$ prefers to form a stoichiometric $\mathrm{SiO}_{2}$ matrix and does not precipitate $\mathrm{nc}-\mathrm{Si}$, corresponding to a small EL intensity at a wavelength of $455 \mathrm{~nm}$ and the much-lower EL intensity at the nearinfrared range. The wavelength of $455 \mathrm{~nm}$ is attributed to the emission of the neutral oxygen vacancy (NOV) defect. The low EL intensity at $455 \mathrm{~nm}$ also reveals that a few NOV defects exist in the PECVD-grown $\mathrm{SiO}_{x}$ film that is prepared at a substrate temperature of $200^{\circ} \mathrm{C}$, which is like a stoichiometric $\mathrm{SiO}_{2}$ matrix. After the substrate temperature is increased to $300^{\circ} \mathrm{C}$, oxygen atoms more easily diffuse into free space than at a substrate temperature of $200^{\circ} \mathrm{C}$. The density of excess $\mathrm{Si}$ atoms in PECVD-grown $\mathrm{SiO}_{x}$ film increases and fewer oxygen atoms react with excess $\mathrm{Si}$ atoms. Because the excess $\mathrm{Si}$ atoms are too few, little nc-Si is precipitated in the PECVD-grown $\mathrm{SiO}_{x}$ film, corresponding to the peak EL wavelength at $\sim 600 \mathrm{~nm}$. Quantum confinement effect contributes to the increase in the energy of the emission as the size of nc-Si decreases. Briefly, the luminescence at a wavelength of $455 \mathrm{~nm}$ for the sample that is prepared at a substrate temperature of $200^{\circ} \mathrm{C}$ is attributed to the emission from NOV defects; however, the luminescence at $600 \mathrm{~nm}$ from the sample prepared at a substrate temperature of $300^{\circ} \mathrm{C}$ is attributed to the emission from the small amount of nc-Si.

For the sample that is prepared at a substrate temperature of 


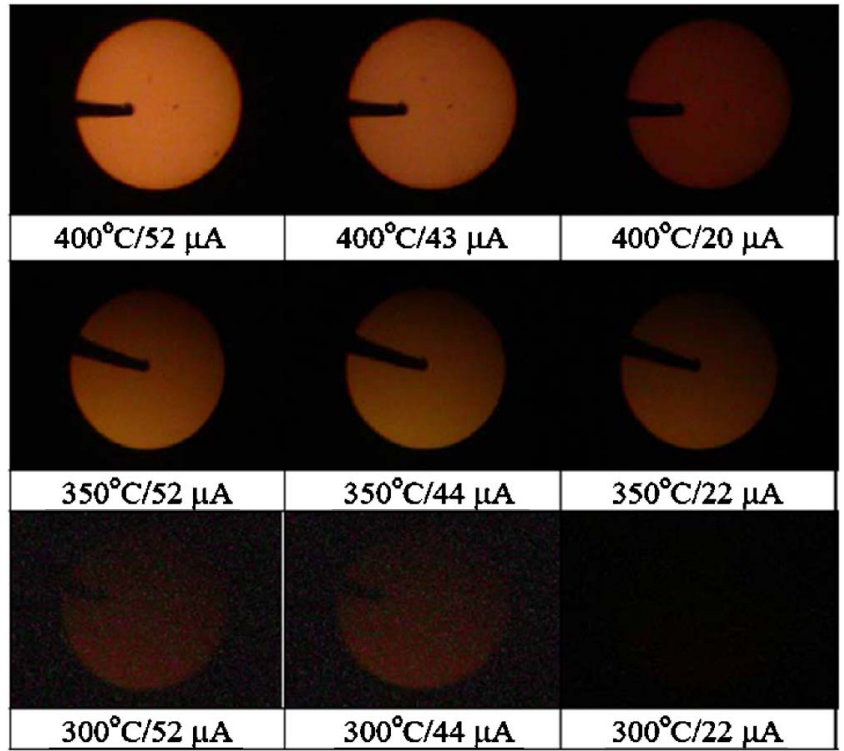

Figure 11. (Color online) Far-field patterns of $\mathrm{ITO}_{\mathrm{SiO}} \mathrm{:}$ : $\mathrm{nc}-\mathrm{Si} / \mathrm{p}-\mathrm{Si} / \mathrm{Al}$ MOSLED.

$350^{\circ} \mathrm{C}$, EL reveals a broad spectrum between 400 and $850 \mathrm{~nm}$ with a peak wavelength of $700 \mathrm{~nm}$ and a fwhm spectral linewidth of $338 \mathrm{~nm}$. The peak wavelength red-shifts from 600 to $700 \mathrm{~nm}$ as the temperature is increased from 300 to $350^{\circ} \mathrm{C}$, revealing the increase in the size of the buried nc-Si. At a low process power and a higher substrate temperature, fewer oxygen atoms are dissociated from molecular $\mathrm{N}_{2} \mathrm{O}$ and oxygen atoms cannot easily remain on the substrate, increasing the density of excess $\mathrm{Si}$ atoms in the PECVDgrown $\mathrm{SiO}_{x}$ film. The EL intensity at $700 \mathrm{~nm}$ of the sample prepared at a substrate temperature of $350^{\circ} \mathrm{C}$ is more than 1 order of magnitude higher than that of the sample prepared at $300^{\circ} \mathrm{C}$, indicating an increase in the densities of nc-Si and excess $\mathrm{Si}$ atoms. During deposition at $350^{\circ} \mathrm{C}$, oxygen atoms abruptly leave the substrate, facilitating the deposition of $\mathrm{Si}$ atoms. Moreover, the fwhm spectral linewidth of $338 \mathrm{~nm}$ for the sample prepared at $350^{\circ} \mathrm{C}$ is much larger than that of $140 \mathrm{~nm}$ for the sample prepared at $300^{\circ} \mathrm{C}$, indicating that the size distribution in the $350^{\circ} \mathrm{C}$ sample is wider and that more excess $\mathrm{Si}$ atoms are embedded in the PECVD-grown $\mathrm{SiO}_{x}$ film. Increasing the substrate temperature to $400^{\circ} \mathrm{C}$ reduces the density of the oxygen atoms and increases the density of excess $\mathrm{Si}$ atoms, increasing the nc-Si density and the luminescent efficiency. The EL spectrum of the sample that is prepared at a substrate temperature of $40{ }^{\circ} \mathrm{C}$ reveals a broadening linewidth from 500 to $850 \mathrm{~nm}$ and a peak wavelength of $618 \mathrm{~nm}$ with a shrunken fwhm spectral linewidth of $296 \mathrm{~nm}$, which are both attributed to the emission of nc-Si. However, an EL spectrum with a peak wavelength of $\sim 450 \mathrm{~nm}$ was clearly observed from PECVD-grown $\mathrm{SiO}_{x}$ film, which is attributed to the luminescence of the oxygen-related NOV defect. At the high substrate temperature, excess oxygen atoms are seldom adsorbed onto the substrate. After annealing at high temperatures, insufficient oxygen atoms can react with $\mathrm{Si}$ atoms and contribute to oxygen vacancies. The luminescence from NOV defects in PECVD-grown $\mathrm{SiO}_{x}$ film at high substrate temperatures reveals the deficiency of oxygen atoms during the formation of nc-Si. This result differs from that obtained for the sample that was prepared at a substrate temperature of $200^{\circ} \mathrm{C}$

At a bias current of $52 \mu \mathrm{A}$, ITO/SiO ${ }_{x}$ :nc-Si/p-Si/Al MOSLEDs prepared at substrate temperatures of 300,350 , and $400^{\circ} \mathrm{C}$ demonstrate red-color emission, which is attributed to the luminescence of $\mathrm{nc}-\mathrm{Si}$, as shown in Fig. 11. Because the density of nc-Si embedded is lowest in the sample that was prepared at a substrate temperature of $300^{\circ} \mathrm{C}$, the far-field pattern of the $300^{\circ} \mathrm{C}$ sample demonstrates the

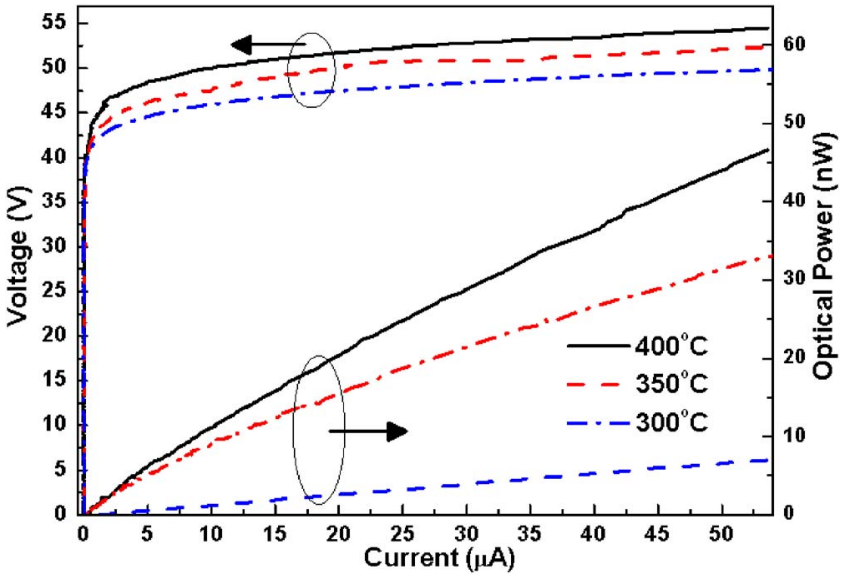

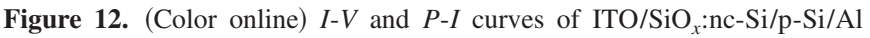
MOSLED.

darkest emission. The optical power is highest in the sample that was prepared at a substrate temperature of $400^{\circ} \mathrm{C}$. As the substrate temperature increases, the optical power of $\mathrm{ITO} / \mathrm{SiO}_{x}: \mathrm{nc}-\mathrm{Si} / \mathrm{p}-\mathrm{Si} / \mathrm{Al}$ MOSLED also increases and the device becomes brighter. In other words, the high substrate temperature facilitates the out-diffusion of oxygen atoms and the increase in the number of excess $\mathrm{Si}$ atoms in the $\mathrm{SiO}_{x}$ film, contributing to the precipitation of nc-Si and increasing the density of nc-Si. However, unanticipated visible EL components at $455 \mathrm{~nm}$ associated with the oxygen vacancy defects are also observed. At a given same-bias current, the increasing EL power confirms the increase in the densities of excess $\mathrm{Si}$ atoms and nc-Si with the deposition temperature during PECVD growth. After annealing for $60 \mathrm{~min}$, the current-voltage $(I-V)$ and power-current $(P-I)$ responses of the forward-biased $\mathrm{ITO}_{\mathrm{SiO}}: \mathrm{nc}-\mathrm{Si} / \mathrm{p}-\mathrm{Si} / \mathrm{Al} \mathrm{di}-$ ode with the buried nc-Si are characterized, as shown in Fig. 12. The threshold voltages of the $\mathrm{ITO}_{\mathrm{SiO}}: \mathrm{nc}-\mathrm{Si} / \mathrm{p}-\mathrm{Si} / \mathrm{Al}$ prepared at 300 , 350 , and $400^{\circ} \mathrm{C}$ are 49,46 , and $44 \mathrm{~V}$, respectively. A maximum output power of $47 \mathrm{nW}$, associated with a $P-I$ slope of $0.84 \mathrm{~mW} / \mathrm{A}$, is obtained. According to the Fowler-Nordheim (FN) plot, a clear linear line reveals that the electron transition is the FN tunneling mechanism. ${ }^{18}$ The $P-I$ slopes of the ITO/SiO $:$ nc-Si/p-Si/Al MOSLEDs are $0.84,0.58$, and $0.14 \mathrm{~mW} / \mathrm{A}$ at substrate temperatures of 400,350 , and $300^{\circ} \mathrm{C}$. The enlarged $P-I$ slope reveals a higher density of luminescent centers, corresponding to the evolution of the $\mathrm{PL}$ and EL spectra. The internal quantum efficiency increases from $5.48 \times 10^{-5}$ to $5 \times 10^{-4}$ with a slope of $3.66 \times 10^{-6} /{ }^{\circ} \mathrm{C}$ as the substrate temperature increases from 300 to $400^{\circ} \mathrm{C}$, as plotted in Fig. 13. The external quantum efficiency increases from 2.27 $\times 10^{-6}$ to $1.6 \times 10^{-5}$. The almost linear increase in the internal quantum efficiency reveals that the density of nc-Si dominates the energy transition in $\mathrm{ITO}_{\mathrm{SiO}}$ : $\mathrm{nc}-\mathrm{Si} / \mathrm{p}-\mathrm{Si} / \mathrm{Al}$ MOSLED, because the variation of substrate temperatures causes the density of excess $\mathrm{Si}$ atoms and the formation of the nc-Si.

\section{Conclusions}

The enhanced EL and external quantum efficiency of metal$\mathrm{SiO}_{x}-\mathrm{Si}$ MOSLEDs that are fabricated on nc-Si-embedded $\mathrm{SiO}_{x}$ PECVD-grown at high substrate temperatures and threshold plasma power are demonstrated. The formation of nc-Si and the associated structural transition were investigated using EELS. The ratio of $\mathrm{SiH}_{4}$ and $\mathrm{N}_{2} \mathrm{O}$ fluences, the process pressure, and the substrate temperature used in the fabrication are $1: 6,60 \mathrm{mTorr}$, and $400^{\circ} \mathrm{C}$, respectively. Because the dissociation energies of the molecular $\mathrm{SiH}_{4}$ and molecular $\mathrm{N}_{2} \mathrm{O}$ are 75.6 and $101.5 \mathrm{kcal} / \mathrm{mol}$, respectively, molecular $\mathrm{N}_{2} \mathrm{O}$ dissociates less easily than molecular $\mathrm{SiH}_{4}$, resulting in the deposition of excess $\mathrm{Si}$ atoms and increasing the density of nc-Si. The threshold voltages of the $\mathrm{ITO} / \mathrm{SiO}_{x}: \mathrm{nc}-\mathrm{Si} / \mathrm{p}-\mathrm{Si} / \mathrm{Al}$ that was pre- 


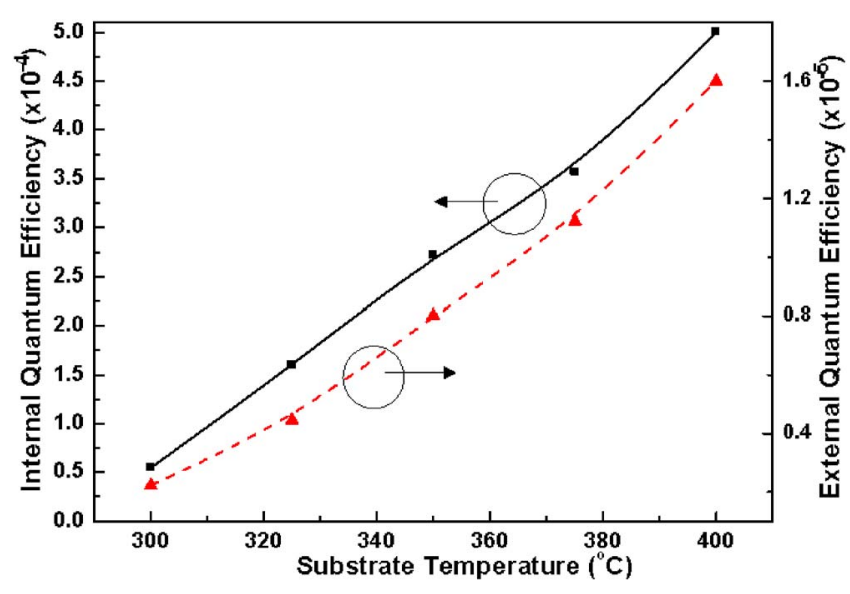

Figure 13. (Color online) Internal and external quantum efficiencies as a function of substrate temperature.

pared at 300,350 , and $400^{\circ} \mathrm{C}$ are 49,46 , and $44 \mathrm{~V}$, respectively. The maximum output power of $47 \mathrm{nW}$, associated with a $P-I$ slope of $0.84 \mathrm{~mW} / \mathrm{A}$, is determined. The internal quantum efficiency increases from $5.48 \times 10^{-5}$ to $5 \times 10^{-4}$ with a slope of 3.66 $\times 10^{-6} /{ }^{\circ} \mathrm{C}$. The external quantum efficiency increases from 2.27 $\times 10^{-6}$ to $1.6 \times 10^{-5}$.

\section{Acknowledgments}

The authors thank the National Science Council of the Republic of China, Taiwan, for financially supporting this research under con- tract no. NSC95-2221-E-002-448, NSC95-2120-M-009-006, NSC95-2221-E-009-282, NSC95-2752-E-229-007-PAE, and NSC96-2752-E-009-007-PAE.

National Taiwan University assisted in meeting the publication costs of this article.

\section{References}

1. G.-R. Lin, C. J. Lin, C. K. Lin, L. J. Chou, and Y. L. Chuen, J. Appl. Phys., 97, 094306 (2005).

2. M. Watanabe, T. Matsunuma, T. Maruyama, and Y. Maeda, Jpn. J. Appl. Phys., Part 2, 37, L591 (1998).

3. C. H. Cho, B. H. Kim, and S. J. Park, Appl. Phys. Lett., 89, 013116 (2006)

4. G. Pucker, P. Bellutti, C. Spinella, K. Gatterer, M. Cazzanelli, and L. Pavesi, J. Appl. Phys., 88, 6044 (2000).

5. M. B. Park and N. H. Cho, Appl. Surf. Sci., 190, 151 (2002).

6. C. J. Lin, C. K. Lin, C. W. Chang, Y. L. Chueh, H. C. Kuo, Eric W. G. Diau, L. J. Chou, and G.-R. Lin, Jpn. J. Appl. Phys., Part 1, 45, 1040 (2006).

7. H. Morisaki, F. W. Ping, H. Ono, and K. Yazawa, J. Appl. Phys., 70, 1869 (1991).

8. O. Madelung, Introduction to Solid State Theory, Chap. 6, Springer-Verlag, Berlin (1996).

9. S. Donati, Photodetectors Devices, Circuits, and Applications, p. 11, Prentice Hall, Englewood Cliffs, NJ (2000).

10. F. Priolo, G. Franzo, D. Pacifici, V. Vinciguerra, F. Iacona, and A. Irrera, J. Appl. Phys., 89, 264 (2001)

11. D. Kovalev, J. Diener, H. Heckler, G. Polisski, N. Kunzner, and F. Koch, Phys. Rev. B, 61, 4485 (2000).

12. C. Garcia, B. Garrido, P. Pellegrino, R. Ferre, J. A. Moreno, J. R. Morante, L. Pavesi, and M. Cazzanelli, Appl. Phys. Lett., 82, 1595 (2003)

13. B. H. Augustine, E. A. Irene, Y. J. He, K. J. Price, L. E. McNeil, K. N. Christensen, and D. M. Maher, J. Appl. Phys., 78, 4020 (1995).

14. C. Delerue, G. Allan, and M. Lannoo, Phys. Rev. B, 48, 11024 (1993),

15. S. H. Bauer and John A. Haberman, IEEE J. Quantum Electron., QE-14, 233 (1978).

16. T. A. Cleland and D. W. Hess, J. Electrochem. Soc., 136, 3103 (1989),

17. T. K. S. Wong, B. Liu, B. Narayanan, V. Ligatchev, and R. Kumar, Thin Solid Films, 462-463, 156 (2004).

18. M. Lenzlinger and E. H. Snow, J. Appl. Phys., 40, 278 (1969). 